\title{
Cytarabine/Hydroxyurea Regimen
}

National Cancer Institute

\section{Source}

National Cancer Institute. Cytarabine/Hydroxyurea Regimen. NCI Thesaurus. Code C10328.

A chemotherapy regimen consisting of cytarabine and hydroxyurea that may be used in the treatment of acute myeloid leukemia (AML). 